\title{
Ultra-Wideband Radar Measurements Over Bare and Snow-Covered Saline Ice
}

S. Gogineni and P. Kanagaratnam

Radar Systems \& Remote Sensing Laboratory

University of Kansas

2291 Irving Hill Rd., Lawrence, KS 66045-2969, USA

TEL: 913/864-7734, FAX: 913/864-7789

E-mail: gogineni@rsl.ukans.edu

\author{
K. Jezek \\ Byrd Polar Research Center, 108 Scott Hall \\ The Ohio State University \\ 1090 Carmack Road, Columbus, Ohio 43210 USA \\ TEL: 614/292-7973 , FAX: 614/292-4697 \\ E-mail: jezek@iceberg.mps.ohio-state.edu
}

Abstract-We developed an ultra-wideband radar operating over frequencies from $500 \mathrm{MHz}$ to $18 \mathrm{Ghz}$ and used it in conjunction with a plane-wave illuminator to perform radar backscatter measurements over pancake, bare and snowcovered saline ice. The ice was grown in an outdoor pond at the U.S. Army Cold Regions Research and Engineering Laboratory, Hanover, NH. Data were acquired over incidence angles from $0^{\circ}$ to $50^{\circ}$ with $\mathrm{VV}$ and $\mathrm{HH}$ polarizations. Data were also collected on surface roughness, snow properties and ice structure.

The combination of wide bandwidth and plane-wave illumination allowed us uniquely to identify returns from airsnow and snow-ice interfaces. Retums from the snow-ice interface were about $10 \mathrm{~dB}$ higher than those from the snowair interface. At $0^{\circ}$ incidence scattering from bare saline ice varied little with frequency over the frequency range from 5 to $18 \mathrm{GHz}$, whereas scattering from pancake ice increased from about $16 \mathrm{~dB}$ at $5 \mathrm{GHz}$ to $27 \mathrm{~dB}$ at $18 \mathrm{GHz}$. In contrast scattering from snow-covered ice decreased by about $10 \mathrm{~dB}$ over the same frequency range. For both bare and snowcovered saline ice, the scattering coefficient decreased by more than $40 \mathrm{~dB}$ with over the angular region from $0^{\circ}$ and $30^{\circ}$. The rapid decay of the scattering coefficient is indicative of the presence of a coherent component near vertical and of the dominance of surface scattering over this angular region.

\section{INTRODUCTION}

During the 1994 and 1995 winter seasons we made radar backscatter measurements over simulated sea ice at the U.S. Army Cold Regions Research and Engineering Laboratory (CRREL), Hanover, NH. The main goal of our research was to determine primary scattering mechanisms by measuring both radar scattering signatures over a wide range of frequencies in conjunction with detailed observations of surface and volume characteristics of the ice under study. The radar measurements are a small part of a multidisciplinary investigation aimed at developing forward and inverse scattering models for interpreting remotely sensed data in terms of the geophysical parameters of sea ice [1].

We used an ultra-wideband radar consisting of an antenna operated in the near field to simulate plane waves to collect the backscatter data reported here. We used the concept of a compact antenna range to simulate plane waves [2]. We acquired radar data on smooth bare and snow-covered saline ice, and pancake ice. Contemporaneous measurements were made of surface roughness, salinity, temperature and internal structure of the ice as well as measurements of snow including thickness, grain size and density. We collected data over the frequency range from $500 \mathrm{MHz}$ to $18 \mathrm{GHz}$ and incidence angles from $0^{\circ}$ to $50^{\circ}$ with both $\mathrm{VV}$ and $\mathrm{HH}$ polarizations.

The results from our experiments show that scattering from bare saline ice is dominated by surface scatter at frequencies less than about $10 \mathrm{GHz}$ and incidence angles less than $30^{\circ}$. We also observed that scattering from snow-covered saline ice is about $3 \mathrm{~dB}$ higher than that for bare saline ice at $30^{\circ}$ at 5 $\mathrm{GHz}$.

In this paper we provide a brief summary of the system used for data collection, the experiments and their results, and the conclusions based on these results.

\section{SYSTEM AND EXPERIMENT DESCRIPTION}

To accomplish our objective of identifying the primary scattering mechanisms, we needed a system with fine-range resolution to resolve signals from different depths of ice and provide exceptional angular resolution to estimate accurately the scattering response. We developed an ultra-wideband radar using an HP 8722C Vector Network Analyzer operated as a step-frequency radar and used a 42 -inch offset parabola operated in the near field to simulate plane waves.

During the 1994 experiments we used a broadband (2 to 18 GHz) TEM horn as the feed and optimized its location to obtain plane-wave illumination at about six feet from the reflector. During 1995, we employed a bow-tie strip-slot line feed capable of operation over the frequencies between 500 $\mathrm{MHz}$ and $18 \mathrm{GHz}$. Nominally we operated the radar over a bandwidth of $16 \mathrm{GHz}$ with a step size of $10 \mathrm{MHz}$. We calibrated the radar at the end of each data run with an 8-inch metal sphere.

In 1994 we collected radar data on bare saline ice and snow-covered saline ice with snow thickness of about $7 \mathrm{~cm}$ at incidence angles between $0^{\circ}$ and $30^{\circ}$ with VV polarization. During 1995, we collected data on bare saline ice and pancake ice over incidence angles between $0^{\circ}$ and $50^{\circ}$ with VV and $\mathrm{HH}$ polarizations. Pancake ice was simulated by using a 
motor-driven paddle to produce wave action in an outdoor pond as frazil ice formation commenced. We also acquired data at $0^{\circ}$ to obtain probability density functions by collecting more than 100 independent samples for separating coherent and incoherent scattering terms.

\section{SIGNAL PROCESSING AND RESULTS}

Frequency-domain data collected with the vector network analyzer are windowed and Fourier transformed to obtain time-domain or range-domain representation of the signal. Next this signal is range-gated to isolate ice returns from clutter and integrated over the illuminated area to compute total power return. Since the measurements were made using plane waves, the fields do not decay as a function of range. The scattering coefficient is determined from the power return as

$$
\begin{aligned}
& \sigma^{0}=\frac{P_{r} \sigma_{c}}{P_{c} A_{i l l}} \text { where } \\
& P_{r}=\text { power return from the ice } \\
& P_{c}=\text { power return from the calibration target } \\
& A_{\text {ill }}=\text { illuminated area } \\
& \sigma_{c}=\text { radar cross section of the calibration target } \\
& \sigma^{0}=\text { scattering coefficient }
\end{aligned}
$$

Fig. 1 shows power return as a function of range for snowcovered saline ice at $0^{\circ}$. The first small peak at about $2 \mathrm{~m}$ is the signal reflected by the snow-air interface and the second peak at about $2.1 \mathrm{~m}$ is from the snow-ice interface. The return from the snow-ice interface is about seven times larger than that from the snow-air interface. The higher return is the result of higher dielectric discontinuity at the snow-ice interface. Using a resonant monopole antenna we measured the real part of the dielectric constant of snow and ice as 3.5 and 1.17 , respectively. The corresponding reflection coefficients for snow-ice and snow-air interfaces are 0.266 and 0.0406 . The range plot also shows the exceptional range resolution capability of our radar.

Figs. $2 \mathrm{a}$ and $2 \mathrm{~b}$ show the angular response of the scattering coefficients for bare and snow-covered saline ice and pancake ice at $\mathrm{C}$ and $\mathrm{Ku}$ bands. For bare and snow-covered saline ice the scattering coefficient decreased by more than $40 \mathrm{~dB}$ when the incidence angle increased from $0^{\circ}$ to $30^{\circ}$. The scattering coefficient decay with the incidence angle between $30^{\circ}$ and $55^{\circ}$ is fairly small because of the presence of volume scattering. At large incidence angles scattering from pancake ice is about $10 \mathrm{~dB}$ higher than that for bare ice.

Fig. 3 shows that $\sigma^{0}$ for $\mathrm{VV}$ polarization at $5.5 \mathrm{GHz}$ is a function of incidence angle along with showing comparison data from field measurements made during the International
Arctic Ocean Experiment (IAOE) for pancake ice. The backscatter measurements were on pancake ice growing in leads during the transit phase of IAOE. The average $\sigma^{0}$ from the IAOE data, along with maximum and minimum measurements (as extended bars), are shown in here. The average scattering for simulated pancake ice is about $5 \mathrm{~dB}$ lower than that observed during IAOE. The lower scattering may be the result of the formation of elongated pancakes in the laboratory because of less vigorous wave action.

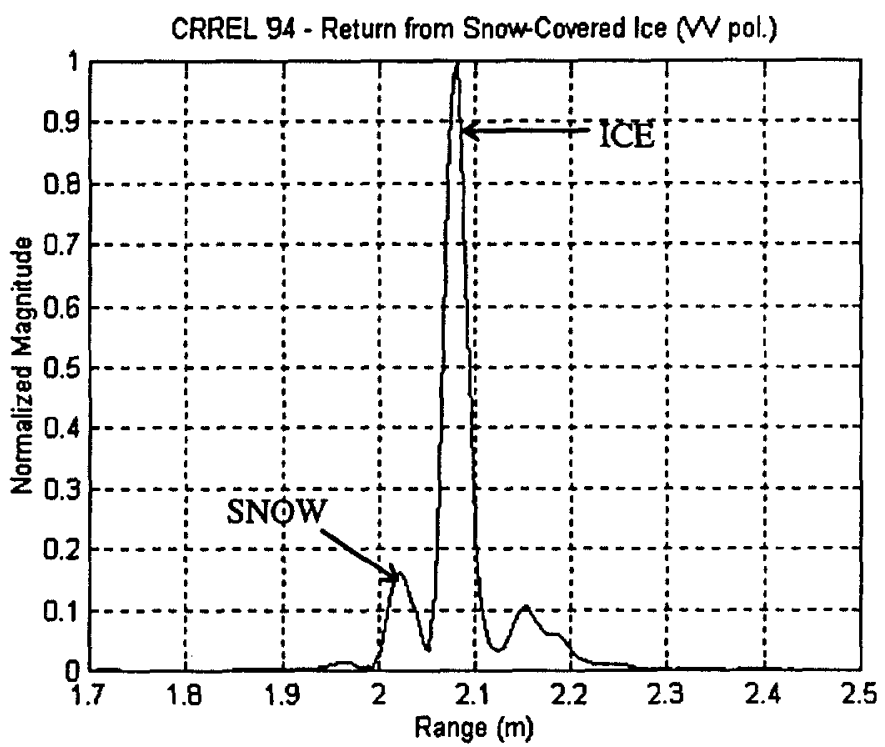

Fig. 1 Return from snow-covered ice at $0^{\circ}$.

Fig. 4 shows the frequency response of scattering from bare and snow-covered saline ice and pancake ice at $20^{\circ}$. The scattering coefficient generally increased with frequency for the three ice types with the increase being much higher for pancake ice. The slight decrease of scattering coefficient for bare and snow-covered ice at frequencies between 14 and 18 $\mathrm{GHz}$ is an artifact associated with filtering of data and antenna feed. Although we corrected for the droop introduced by the filter used for range gating, its effect cannot completely be eliminated.

\section{CONCLUSIONS}

The use of plane-wave illumination and wide bandwidth allowed us to determine experimentally the relative contributions to the backscattered signal and the scattering response of smooth surfaces. The results from our experiments indicate that the backscattered signal from saline ice is dominated by contributions from the ice surface at frequencies less than about $10 \mathrm{Ghz}$ at incidence angles less than $30^{\circ}$. 

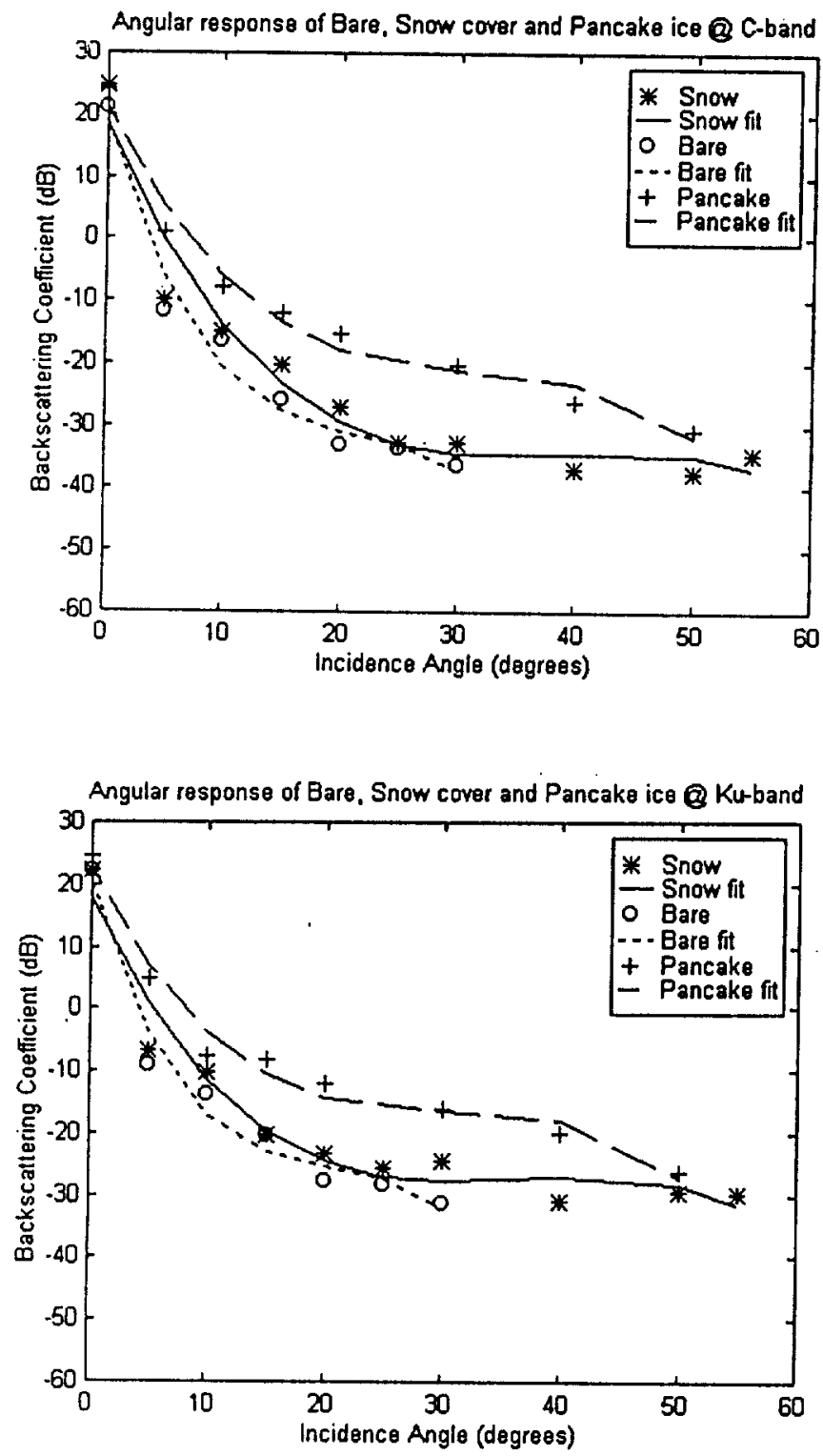

Fig. 2 Angular responses of bare, snow-covered, and pancake ice at (a) $\mathrm{C}$ band and (b) Ku band.

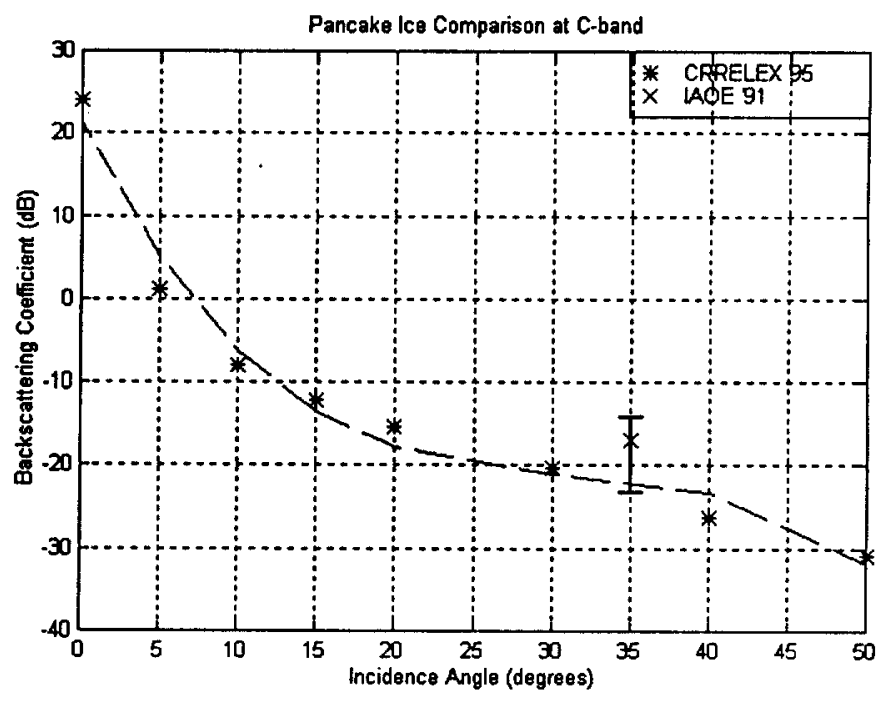

Fig. 3 Comparison between field and laboratory measurement of pancake ice.

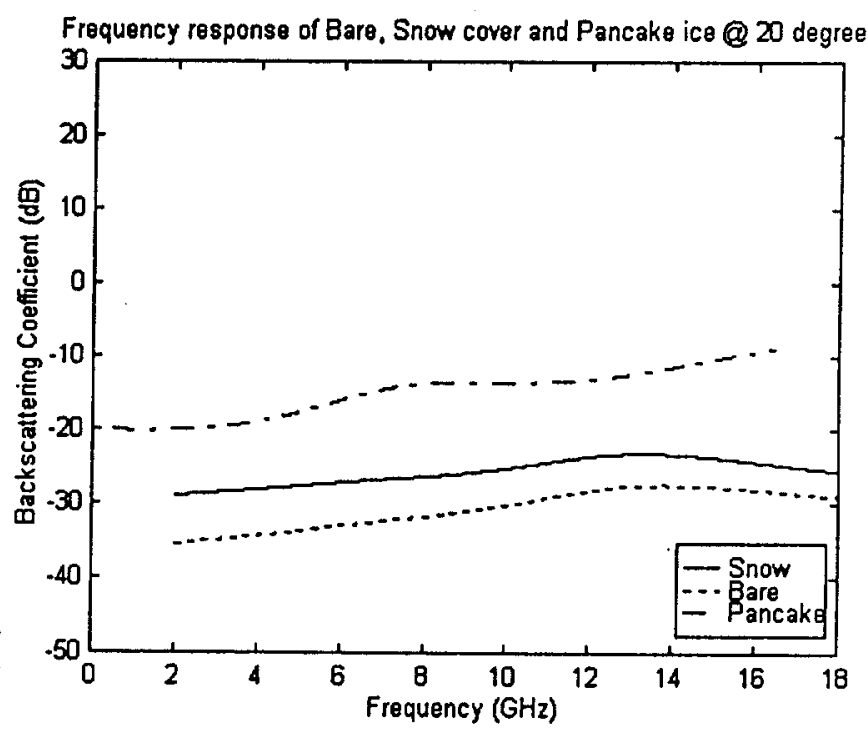

Fig. 4 Frequency response of bare, snow-covered, and pancake ice at $20^{\circ}$.

\section{REFERENCES}

[1] S. Gogineni, K. Jezek, L. Peters, J. Young, S. Beaven, and E. Nassar, "Application of plane waves for accurate measurement of microwave scattering from geophysical surfaces," IEEE Trans. on Geoscience and Remote Sensing, vol. 33, pp. 627-633, 1995.
[2] K. Jezek, P. Gogineni, L.Peters, J.Young, S. Beaven, E.Nassar, and I.Zabel, "Microwave scattering from saline ice using plane wave illumination," IGARSS'94 Digest, 8-12 Aug. JPL, Pasadena, CA, pp. 493-495, 1994. 